16 a 18 de outubro de 2019 - Campinas | Brasil

\title{
STUDY OF EROSION IN CONCRETE HYDRAULIC SURFACE USING A COMPUTATIONAL FLUID DYNAMIC
}

\section{Guilherme R. Gallani*, Gianandrea V. Messa, José Gilberto D. Filho.}

\section{Abstract}

The erosion causes several damages to the hydraulic surfaces whether by cavitation or by abrasion, and can compromise structures safety. In the first one, the water high speed reduces its vapour pressure and bubbles implosion quickly damages the material whereas in the second one, water-solid mix slowly removes surfaces material. It is clear that different materials show various behaviors when exposed to erosion by abrasion and a number of apparatuses were depeloped to evaluate the resistance to erosion by abrasion. In this research, the aim was to develop through computational fluid dynamic a mathematical method to evaluate the concrete resistance to erosion by abrasion, based on existing aparattus.

\section{Key words: computational fluid dynamic, water-solid mix erosion, hydraulic structures}

\section{Introduction}

According to Liu et al. (2006), erosion by abrasion affects the concrete in three different steps: firstly, the cement is worn by water-solid mix speed; secondly the impact causes fissures and exposes the coarse aggregate; finaly the whole material is removed and the erosion increases. To measure the concrete behavior and to evaluate its resistance to erosion by abrasion, several apparatuses have been developed. Basically, they all consist in determining mass variation over time. Liu et al (2006) presents a small compilation of these apparatuses, in addition to developing an own method, where a jet is applied against a specimen.

In the literature, some numerical models were developed in apparatus with erosive jets applied against a test body. Based on these studies, Messa et al. (2017) evaluated the effect of different parameters on the results.

In this work, based on the research of Messa et al. (2017), it was sought to numerically simulate the results obtained by Liu et al. (2012).

\section{Results and Discussion}

In the apparatus of Liu et al. (2006), shown in figure 1, a free jet is applied at $10 \mathrm{~m} / \mathrm{s}$ against the test body. Different from the adopted one, in the numerical modeling, the jet was considered submerged, since, with adequate boundary conditions, they do not affect the results, besides requiring less computational resource.
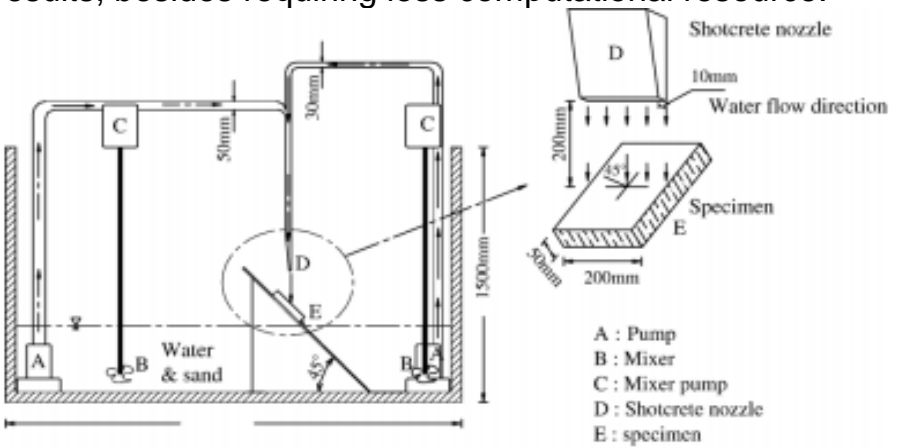

Image 1. Apparatus used by Liu et al (2006).

Simulations with different mesh qualities were done with the intention of obtaining optimized results. Figure 2 shows jet pressure values at $10 \mathrm{~mm}$ above the test body on the central axis of the jet. The latest simulations rely on more refined meshes.

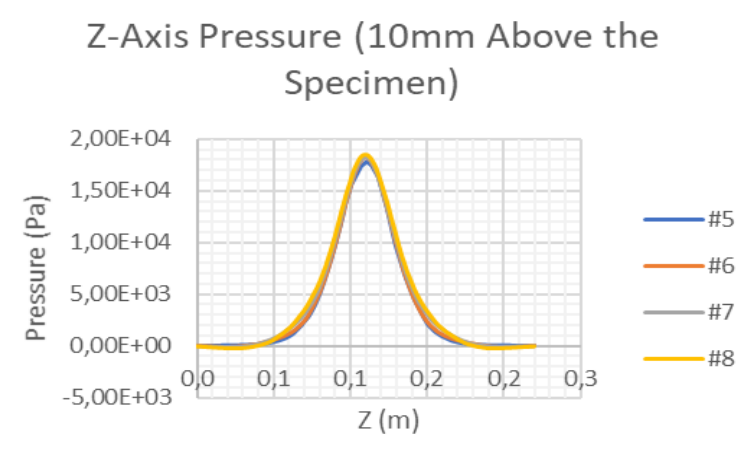

Image 2. Pressure on central axis of test piece.

Image 3 shows a visual comparison between the actual and numerical values. The difference in the edges is due to the size of the specimen in relation to the nozzle, higher in numerical modeling.

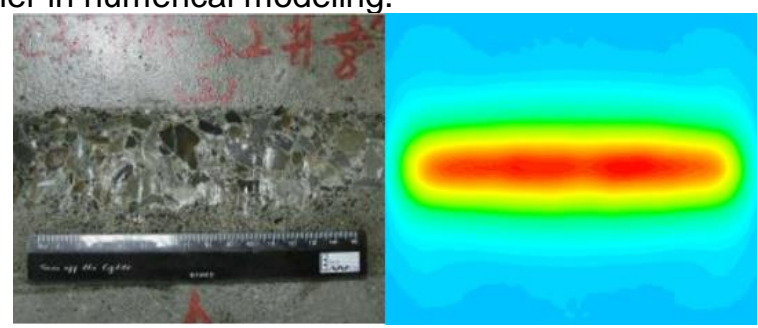

Image 3. Empirical and numerical erosion results.

Conclusions

Although analyzes for different concrete types have to be done, the results are promising and require hours to obtain without wasting materials and resources.

\section{Acknowledgement}

To Gianandrea and José Gilberto, for time and shared knowledge.

${ }^{1}$ LIU, Yu-Wen; YEN, Tsong; HSU, Tsao-Hua. Abrasion erosion of concrete by water-borne sand. Cement and Concrete Research, v. 36, n. 10, p. 1814 1820,2006

${ }^{2}$ LIU, Yu-Wen; CHO, Shi-Wei; HSU, Tsao-Hua. Impact abrasion of hydraulic structures concrete. Journal of marine science and technology, v. 20, n. 3, p. $253-258,2012$

3 MESSA, Gianandrea Vittorio; MALAVASI, Stefano. The effect of submodels and parameterizations in the simulation of abrasive jet impingement tests. Wear, v. 370, p. 59-72, 2017. 